\title{
Association study of +45G15G(T/G) and +276(G/T) polymorphisms in the adiponectin gene in patients with polycystic ovary syndrome
}

\author{
LAN LI $^{1 *}$, JI-HYUN YUN ${ }^{1 *}$, JAE-HYUN LEE ${ }^{2}$, SANGJIN SONG ${ }^{3}$, \\ BUM-CHAE $\mathrm{CHOI}^{3}$ and KWANG-HYUN BAEK ${ }^{1}$
}

\begin{abstract}
${ }^{1}$ Department of Biomedical Science, CHA University, CHA General Hospital, Seoul 135-081; ${ }^{2}$ Dae-Jin High School, Seoul 139-711; ${ }^{3}$ Department of Obstetrics and Gynecology, CL Women's Hospital, Kwangju 502-800, Republic of Korea
\end{abstract}

Received August 30,2010; Accepted November 2, 2010

DOI: $10.3892 / \mathrm{ijmm} .2010 .565$

\begin{abstract}
The polycystic ovary syndrome (PCOS) is considered as one of the most common endocrine and reproductive dysfunctional diseases. Recent research for genetic variants has identified genetic influences between the polymorphisms of the adiponectin gene and the metabolic syndromes. The aim of our study was to investigate the relationship between single nucleotide polymorphisms (SNPs) in the adiponectin gene and PCOS. Two SNPs, $+45 \mathrm{G} 15 \mathrm{G}(\mathrm{T} / \mathrm{G})$ and $+276(\mathrm{G} / \mathrm{T})$, which are found in exon 2 and intron 2 , respectively, of the adiponectin gene, were genotyped by PCR-RFLP. Out of 303 women studied for the $+45 \mathrm{G} 15 \mathrm{G}(\mathrm{T} / \mathrm{G})$ and $+276(\mathrm{G} / \mathrm{T})$ SNPs, 144 had PCOS and 159 were healthy controls. No association was found between the $+45(\mathrm{~T} / \mathrm{G})$ SNP and PCOS $(\mathrm{P}=0.3558, \mathrm{OR}=0.83,95 \%$ confidence interval), per contra to the association between $+276(\mathrm{G} / \mathrm{T}) \mathrm{SNP}$ and PCOS $(\mathrm{P}=0.0126, \mathrm{OR}=0.60,95 \%$ confidence interval). These results indicate that the SNP of $+276(\mathrm{G} / \mathrm{T})$ is strongly associated with PCOS. However, the $+45(\mathrm{~T} / \mathrm{G}) \mathrm{SNP}$ is not associated with PCOS.
\end{abstract}

\section{Introduction}

The polycystic ovary syndrome (PCOS) is a common multifactorial disease, also considered as an endocrine syndrome with polymorphic clinical manifestations, including hyperandrogenism and chronic anovulation (1-5). The current diagnostic criteria are based on the 2003 American

Correspondence to: Dr Kwang-Hyun Baek, CHA Stem Cell Institute, Department of Biomedical Science, CHA University, CHA General Hospital, 606-16 Yeoksam 1-Dong, Gangnam-Gu, Seoul 135-081, Republic of Korea

E-mail: baek@cha.ac.kr

*Contributed equally

Key words: adiponectin; polycystic ovary; single nucleotide polymorphism
Society for Reproductive Medicine/European Society of Human Reproduction and Embryology (ASRM/ESHRE) Rotterdam consensus $(6,7)$. So far, the aetiology of PCOS has not been fully elucidated, but correlation studies have found that PCOS is likely to be hereditary, since a sister with PCOS increases the risk of PCOS up to $46 \%$ (8). Therefore, the study of the PCOS candidate gene will reveal the fundamental mechanism and complication of PCOS.

A large number of studies have shown that there is a close relationship between insulin resistance (IR) and PCOS. IR is a main factor in the development of PCOS, and about $64.4 \%$ of PCOS patients have IR (9). PCOS patients, whether obese or not, have different levels of IR and hyperinsulinemia and IR is independent of obesity. IR leads to obstacles in fat mobilization and utilization, becoming an important risk factor for obesity. Furthermore, lipocytes, one of the major insulin target cells, can produce a variety of factors involved in the development of IR $(10,11)$.

Adiponectin is one of the most abundant adipokines and accounts for $0.01 \%$ or $3-30 \mu \mathrm{g} / \mathrm{ml}$ of the total plasma protein (12). Adiponectin is secreted by lipocytes and is composed of 224 amino acid peptides. Several studies have shown that adiponectin plays an important role in the process of glucose regulation and lipid metabolism. Moreover, adiponectin can increase skeletal muscle fatty acid oxidation and peripheral tissue sensitivity to insulin and can inhibit hepatic gluconeogenesis. It has been suggested that adiponectin has a protective effect on the development of atherosclerosis $(13,14)$. In different animal models for obesity and diabetes, adiponectin was found to correlate with the insulin sensitivity index (15). Furthermore, adiponectin has been shown to be an important inflammatory response regulator (16).

Adiponectin is a collagen-like protein which is secreted and produced by adipose tissue and its coding gene is located on human chromosome $3 \mathrm{q} 27$. It has alternative names, including ACDC, APM1, ACRP30 and GBP28. Studies of the genetic association have shown that the adiponectin gene polymorphisms are closely related to obesity, type 2 diabetes (T2D) and IR. Approximately 6 adiponectin gene polymorphisms have been identified and have been associated with metabolic disorders in different ethnic populations of different environmental factors and genetic backgrounds. 
These include the following single nucleotide polymorphisms (SNPs):-11426(A/G), -11391(A/G), -11377(C/G), +45(T/G), $+276(\mathrm{G} / \mathrm{T})$ and $\mathrm{H} 111 \mathrm{Y}(\mathrm{C} / \mathrm{T})$ (11-12,17-21). Intriguingly, SNPs $+45(\mathrm{~T} / \mathrm{G})$ and $+276(\mathrm{G} / \mathrm{T})$ which are located in exon 2 and intron 2 of the adiponectin gene, respectively, have been found to be strongly associated with obesity, IR and T2D in Asian populations. In this study, we assessed the association of SNPs $+45(\mathrm{~T} / \mathrm{G})$ and $+276(\mathrm{G} / \mathrm{T})$ in the adiponectin gene with PCOS in the Korean population.

\section{Materials and methods}

Subjects. All of the PCOS patients and controls were Korean women which were recruited from the Fertility Center of the CHA General Hospital in Seoul, Korea. Informed consent was obtained from all patients. Among 303 Korean women, 144 had PCOS, while the remaining 159 were healthy control subjects. The diagnosis of PCOS was based on the criteria proposed by the 2003 ASRM/ESHRE Rotterdam consensus. Blood samples were collected in tubes containing EDTA as an anticoagulant and stored at $4{ }^{\circ} \mathrm{C}$. Genomic DNA was extracted from the blood of PCOS patients and control women. The study was approved by the Institutional Review Board.

Biochemical determinations. Blood samples were obtained from PCOS patients and control subjects for chemical analyses of FSH, LH, TSH, prolactin, DHEA-S, and E2 as indicators of discrimination.

Genetic analysis. Two SNPs were genotyped by the PCRbased RFLP analysis for all subjects. Primers and restriction enzymes used are shown in Table I. The PCR amplification conditions used for $+45 \mathrm{G} 15 \mathrm{G}(\mathrm{T} / \mathrm{G})$ were as follows: $94^{\circ} \mathrm{C}$ for $5 \mathrm{~min}$, followed by 30 cycles of $35 \mathrm{sec}$ at $94^{\circ} \mathrm{C}, 30 \mathrm{sec}$ at $58.8^{\circ} \mathrm{C}$, and $30 \mathrm{sec}$ at $72^{\circ} \mathrm{C}$. PCR conditions for $+276(\mathrm{G} / \mathrm{T})$ were as follows: $95^{\circ} \mathrm{C}$ for $5 \mathrm{~min}$, followed by 35 cycles of $30 \mathrm{sec}$ at $95^{\circ} \mathrm{C}, 30 \mathrm{sec}$ at $62^{\circ} \mathrm{C}$, and $30 \mathrm{sec}$ at $72^{\circ} \mathrm{C}$. The PCR products were purified using Bioneer's AccuPrep PCR purification kit (Bioneer, Daejeon, Korea) and were digested with SmaI (New England Biolabs, Beverly, MA, USA) for $6 \mathrm{~h}$ at $25^{\circ} \mathrm{C}$ or $B s m \mathrm{I}$ (New England Biolabs) for $14 \mathrm{~h}$ at $65^{\circ} \mathrm{C}$ for SNPs $+45(\mathrm{~T} / \mathrm{G})$ and $+276(\mathrm{G} / \mathrm{T})$, respectively. The digested DNA fragments were electrophoresed on a $2 \%$ agarose gels containing ethidium bromide and visualized by an ultraviolet transilluminator. In regard to the SNP $+45(\mathrm{~T} / \mathrm{G})$, a single 390-bp band indicates homozygosity for the T allele; the two bands, 217- and 173-bp, indicate homozygosity for the G allele; the presence of three fragments, 390-, 217- and 173-bp bands, indicate heterozygosity for the $\mathrm{T}$ or $\mathrm{G}$ allele (Fig. 1). As for the SNP $+276(\mathrm{G} / \mathrm{T})$, presence of a single 468-bp band indicates homozygosity for the $\mathrm{G}$ allele; presence of two fragments, 320- and 148-bp, indicates homozygosity for the $\mathrm{T}$ allele; and three fragments, 468-, 320- and 148-bp indicate heterozygosity for the $\mathrm{G}$ and the T allele (Fig. 2).

Statistical analysis. Genotype and allele frequencies were compared between patients and controls by the $\chi^{2}$ test. Analyzed haplotypes composed of SNPs were evaluated with HapAnalyzer. P-values of $<0.05$ were considered as statistically significant.

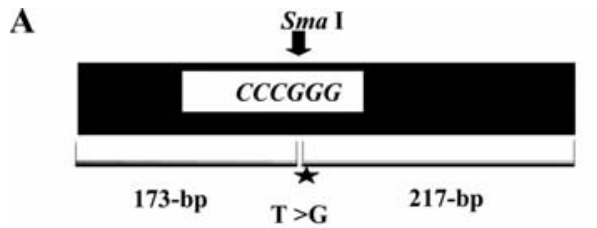

390-bp : Homozygosity for T allele
173- and 217-bp : Homozygosity for G allele
390-, 173- and 217-bp : Heterozygosity for $T$ and $G$

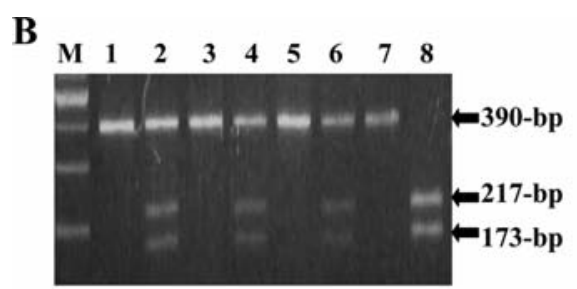

Lane 1: TT Lane 2: TG Lane 3: TT Lane 4: TG

Lane 5: TT Lane 6: TG Lane 7: TT Lane 8: GG

Figure 1. (A) Structure of exon 2 of the adiponectin gene. The arrow indicates the restriction site of SmaI. The site of the adiponectin +45 (T/G) polymorphism is marked with an asterisk. When the sequence contains the $\mathrm{G}$ allele, SmaI restricts the site and produces two fragments, 217-bp and 173-bp. Presence of the T allele makes one fragment, 390-bp. (B) RFLP analysis of the $\mathrm{T} / \mathrm{G}$ polymorphism in exon 2 of the adiponectin gene.

A

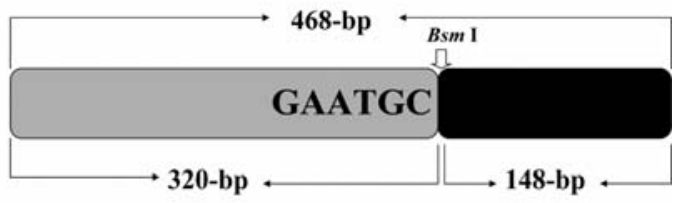

468-bp : Homozygosity for the G allele

320- and 148-bp : Homozygosity for the $T$ allele

468-, 320- and 148-bp : Heterozygosity for the $G$ and $T$ allele

B

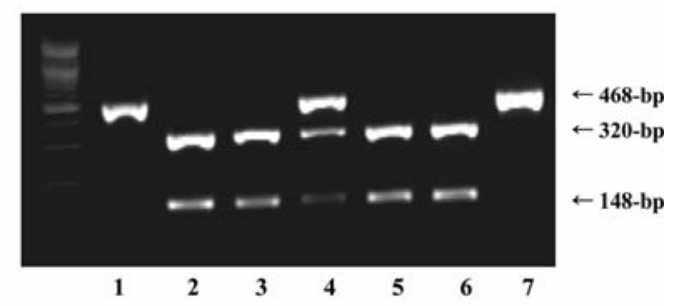

\begin{tabular}{|llll|}
\hline 1: GG & 2: TT & 3: TT & \\
4: TG & 5: TT & 6: TT & 7: GG \\
\hline
\end{tabular}

Figure 2. (A) Structure of intron 2 of the adiponectin gene. When the sequence has the T allele, BsmI recognizes the site and make two fragments, 320-bp, 148-bp. Presence of the G allele makes one fragment, 468-bp. (B) RFLP analysis of the $\mathrm{G} / \mathrm{T}$ polymorphism in intron 2 of the adiponectin gene. 
Table I. Oligonucleotide sequences for detection of adiponectin gene SNP +45(T/G) and +276(G/T).

\begin{tabular}{|c|c|c|c|c|}
\hline & Length & $\mathrm{Tm}$ & Restriction enzyme & Incubation \\
\hline \multicolumn{5}{|l|}{$+45(\mathrm{~T} / \mathrm{G}) \mathrm{SNP}$ primers } \\
\hline (F) AGGTGGGCTGCAATATTCAG & 20 & 58.8 & SmaI & $6 \mathrm{~h}$ \\
\hline (R) CCTGGATCTCCTTTCTCACC & 20 & & & \\
\hline \multicolumn{5}{|l|}{$+276(\mathrm{G} / \mathrm{T}) \mathrm{SNP}$ primers } \\
\hline (F) TCTCTCCATGGCTGACAGTG & 20 & 62 & BsmI & $14 \mathrm{~h}$ \\
\hline (R) AGATGCAGCAAAGCCAAAGT & 20 & & & \\
\hline
\end{tabular}

Table II. Biochemical and clinical characteristics of normal controls $(n=159)$ and PCOS patients $(n=144)$.

\begin{tabular}{|c|c|c|c|c|}
\hline \multirow{2}{*}{$\frac{\text { Characteristics }}{\text { BMI }\left(\mathrm{kg} / \mathrm{m}^{2}\right)}$} & \multicolumn{2}{|c|}{ Controls $(\mathrm{n}=159)$} & \multicolumn{2}{|c|}{ PCOS patients $(\mathrm{n}=144)$} \\
\hline & $20.73 \pm 2.36$ & $(16.61-27.70)$ & $23.22 \pm 3.88$ & $(16.18-37.32)$ \\
\hline Waist/hip ratio (WHR) & $0.80 \pm 0.07$ & $(0.70-0.91)$ & $0.82 \pm 0.06$ & $(0.67-1.49)$ \\
\hline Hyperandrogenism and oligo- or amenorrhea & \multicolumn{2}{|c|}{$\mathrm{n}=0 \quad(0.00 \%)$} & \multicolumn{2}{|c|}{$\mathrm{n}=22(15.30 \%)$} \\
\hline Hyperandrogenism and polycystic ovaries & \multicolumn{2}{|c|}{$\mathrm{n}=0 \quad(0.00 \%)$} & \multicolumn{2}{|c|}{$\mathrm{n}=12 \quad(8.33 \%)$} \\
\hline Oligo- or amenorrhea and polycystic ovaries & \multicolumn{2}{|c|}{$\mathrm{n}=0 \quad(0.00 \%)$} & \multicolumn{2}{|c|}{$\mathrm{n}=94(65.28 \%)$} \\
\hline $\begin{array}{l}\text { Hyperandrogenism, oligo- or amenorrhea and } \\
\text { polycystic ovaries }\end{array}$ & \multicolumn{2}{|c|}{$\mathrm{n}=0 \quad(0.00 \%)$} & \multicolumn{2}{|c|}{$\mathrm{n}=15(10.42 \%)$} \\
\hline FSH levels $(\mathrm{mIU} / \mathrm{ml})$ & $6.55 \pm 1.82$ & $(3.00-13.50)$ & $5.81 \pm 1.83$ & $(1.00-19.90)$ \\
\hline LH levels (mIU/ml) & $3.24 \pm 1.48$ & $(1.12-7.10)$ & $8.37 \pm 6.55$ & $(1.00-25.00)$ \\
\hline E2 levels (pg/ml) & $32.47 \pm 15.13$ & $(4.25-64.10)$ & $42.93 \pm 34.58$ & $(5.00-88.50)$ \\
\hline Prolactin levels (ng/ml) & $12.24 \pm 6.48$ & $(4.10-46.40)$ & $13.42 \pm 9.64$ & $(2.30-72.20)$ \\
\hline TSH levels $(\mu \mathrm{IU} / \mathrm{ml})$ & $1.88 \pm 0.94$ & $(0.03-4.06)$ & $2.25 \pm 1.43$ & $(0.46-10.45)$ \\
\hline DHEA-S levels $(\mu \mathrm{g} / \mathrm{dl})$ & $157.86 \pm 55.4$ & $(67.20-257.40)$ & $198.07 \pm 76.5$ & $(45.30-377.20)$ \\
\hline Testosterone levels (ng/ml) & $0.25 \pm 0.15$ & $(0.01-0.54)$ & $0.58 \pm 0.21$ & $(0.06-0.86)$ \\
\hline
\end{tabular}

\section{Results}

The analysis of the clinical and biochemical characteristics of the healthy control subjects and of patients with PCOS are shown in Table II. In regard to the diagnostic criteria of PCOS, we followed the 2003 ASRM/ESHRE Rotterdam consensus (6). According to the criteria, patients are diagnosed with PCOS when they have two of the following three features: oligo- or amenorrhea, clinical or biochemical hyperandrogenism and ultrasonographic polycystic ovarian morphology (6). As shown in Table II, there was difference in the level of TSH, DHEA-S and testosterone for the PCOS patients and control groups. In addition, the level of $\mathrm{LH}$ in PCOS patients was almost twice as much as in the control group. In the PCOS patient group, 22 patients (15.30\%) had hyperandrogenism and oligo- or amenorrhea, 12 patients $(8.33 \%)$ had hyperandrogenism and polycystic ovaries, 94 patients $(65.28 \%)$ had oligo- or amenorrhea and polycystic ovaries, and 15 patients $(10.42 \%)$ had hyperandrogenism, oligo- or amenorrhea and polycystic ovaries (Table II).

To analyze the frequency of the genotypes for SNPs in the adiponectin gene, we performed PCR-RFLP analysis. Table III shows the SNP allele frequency of the TT, TG, GG genotypes of the exon $2 \mathrm{~T} / \mathrm{G}$ polymorphism and of the $\mathrm{GG}$, GT, TT genotypes of the intron $2 \mathrm{G} / \mathrm{T}$ polymorphism for the adiponectin gene in patients with PCOS and control subjects. In the case of $+45(\mathrm{~T} / \mathrm{G})$, the frequency of the TT genotype was slightly higher in the PCOS patient group than in the control group ( $54.9 \%$ vs. $45.3 \%$, respectively); the TG genotype was more frequent in the control group (52.8\%) than in the PCOS patient group (41.0\%); the frequency of the GG genotype was similar between the two groups (patient group, 4.2\%; control group, $1.9 \%)$. Also, for the $+276(\mathrm{G} / \mathrm{T})$ SNP, significantly higher frequency of the GG genotype was shown in the PCOS patient group than in the control group ( $42.4 \%$ vs. $30.2 \%$, respectively); the rate of the GT genotype was slightly higher in the control group than in the PCOS patient group; and the frequency of the TT genotype was remarkably higher in the control group $(15.1 \%)$ than in the PCOS patient group $(6.9 \%)$. In addition, as indicated in Table III, there was no association between the SNP +45(T/G) and the occurence of PCOS. In contrast, the data demonstrate the association between the SNP $+276(\mathrm{G} / \mathrm{T})$ and PCOS patients in Korean women.

\section{Discussion}

Molecular genetic studies have shown that hormone metabolism and energy regulation-related genes, such as CYP19, INSR, LH are involved in the pathogenesis of PCOS (22-26). 
Table III. Genotype and allele frequencies of $+45(\mathrm{~T} / \mathrm{G})$ and $+276(\mathrm{G} / \mathrm{T})$ polymorphisms of the adiponectin gene in women with PCOS and control subjects.

\begin{tabular}{|c|c|c|c|}
\hline Polymorphism & $\operatorname{PCOS}(n=144)$ & Controls $(\mathrm{n}=159)$ & $\mathrm{P}$ \\
\hline \multicolumn{4}{|l|}{$+45(\mathrm{~T} / \mathrm{G})$} \\
\hline \multicolumn{4}{|c|}{ Genotypes, n (\%) } \\
\hline $\mathrm{TT}$ & $79(54.9)$ & $72(45.3)$ & \multirow{3}{*}{0.3558} \\
\hline TG & $59(41.0)$ & $84(52.8)$ & \\
\hline GG & $6 \quad(4.2)$ & $3(1.9)$ & \\
\hline \multicolumn{4}{|l|}{ Alleles, n (\%) } \\
\hline $\mathrm{T}$ & $217(75.3)$ & $228(71.7)$ & \\
\hline $\mathrm{G}$ & $71(24.7)$ & $90(28.3)$ & \\
\hline \multicolumn{4}{|l|}{$+276(\mathrm{G} / \mathrm{T})$} \\
\hline \multicolumn{4}{|c|}{ Genotypes, n (\%) } \\
\hline GG & $61(42.4)$ & $48(30.2)$ & \multirow{3}{*}{0.0126} \\
\hline GT & $73(50.7)$ & $87(54.7)$ & \\
\hline $\mathrm{TT}$ & $10 \quad(6.9)$ & $24(15.1)$ & \\
\hline \multicolumn{4}{|l|}{ Alleles, n (\%) } \\
\hline $\mathrm{G}$ & $195(67.7)$ & $183(57.5)$ & \\
\hline $\mathrm{T}$ & $93(32.3)$ & $135(42.5)$ & \\
\hline
\end{tabular}

There was association between PCOS and the SNP $+276(\mathrm{G} / \mathrm{T})$, but not with the SNP $+45(\mathrm{~T} / \mathrm{G})$.

In the present study, we assessed another metabolism-related gene, adiponectin, and examined the association between the SNPs $+45 \mathrm{G} 15 \mathrm{G}(\mathrm{T} / \mathrm{G})$ and $+276(\mathrm{G} / \mathrm{T})$ in the adiponectin gene and PCOS in Korean women. An association was found between the $+276(\mathrm{G} / \mathrm{T})$ SNP and PCOS, while the $+45(\mathrm{~T} / \mathrm{G})$ SNP was not associated with PCOS in Korean women. To a certain extent, variation of the adiponectin gene determines the overexpression of the phenotype of the metabolic syndrome. However, it has been reported that the polymorphism of the adiponectin gene is not the real reason for the metabolic disorders of PCOS (27); it has been suggested that a certain degree of interaction may exist between adiponectin and steroid hormone activity and synthesis. At present, 13 SNPs have been identified in the adiponectin gene (28), and most of the studies have focused on two SNPs: $+45(\mathrm{~T} / \mathrm{G})$ and $+276(\mathrm{G} / \mathrm{T})$. However, the influence of these two polymorphisms on the adiponectin gene expression or biological function is not fully known, because the SNP $+45(\mathrm{~T} / \mathrm{G})$ is a synonymous polymorphism while the SNP $+276(\mathrm{G} / \mathrm{T})$ is an intronic one.

It has been reported that SNPs $+45(\mathrm{~T} / \mathrm{G})$ and $+276(\mathrm{G} / \mathrm{T})$ in the adiponectin gene are significantly associated with PCOS in Chinese women (29). These two SNPs have been analyzed in various diseases and in different ethnic backgrounds. It has been reported that fasting glucose levels are influenced by the adiponectin $+276(\mathrm{G} / \mathrm{T})$ polymorphism in Korean and Italian populations $(30,31)$. In French and Swedish Caucasians, the $+45(\mathrm{~T} / \mathrm{G})$ and $+276(\mathrm{G} / \mathrm{T})$ polymorphisms have not been associated with T2D (32). However, it has also been indicated that SNPs $+45(\mathrm{~T} / \mathrm{G})$ and $+276(\mathrm{G} / \mathrm{T})$ are strongly associated with type 1 diabetes (T1D), but not with diabetic nephropathy (DN) in Swedish patients (33). Studies have illustrated that the SNP in intron 2 of the adiponectin gene plays an important role in the regulation of adiponectin levels, although the exact cellular mechanism is still not known $(34,35)$.

This is the first report on the association of two SNPs of the adiponectin gene with PCOS patients in Korea. Our results provide insight into the role of the adiponectin gene in the pathogenesis of PCOS in different ethnic backgrounds and also provide an important basis for the early diagnosis and prevention of PCOS.

\section{Acknowledgements}

We sincerely thank the Fertility Center and the Stem Cell Institute at the CHA University and the CHA General Hospital. This study was supported by a grant from the Korea Health 21 R\&D Project, Ministry of Health and Welfare, Korea (01-PJ10-PG6-01 GN13-0002).

\section{References}

1. Sheehan MT: Polycystic ovarian syndrome: diagnosis and management. Clin Med Res 2: 13-27, 2004.

2. Chang WY, Knochenhauer ES, Bartolucci AA and Azziz R: Phenotypic spectrum of polycystic ovary syndrome: clinical and biochemical characterization of the three major clinical subgroups. Fertil Steril 83: 1717-1723, 2005.

3. Stankiewicz M and Norman R: Diagnosis and management of polycystic ovary syndrome: a practical guide. Drugs 66: 903-912, 2006.

4. Nazir F, Saeed S, Malik M, Aziz H, Aliya S and Rana S: Polycystic ovary syndrome (PCOS)-Diagnosis and management in fertility deprivation. Pak J Obstet Gynaecol 12: 59-71, 1999. 
5. Cheung AP: Polycystic ovary syndrome: a contemporary view. J Obstet Gynaecol Can 32: 423-428, 2010.

6. Legro RS: The genetics of polycystic ovary syndrome. Am J Med 98: 9-16, 1995.

7. Rotterdam ESHRE/ASRM-Sponsored PCOS Consensus Workshop Group: Revised 2003 consensus on diagnostic criteria and long-term health risks related to polycystic ovary syndrome. Fertil Steril 81: 19-25, 2004.

8. Yuping X: Polycystic ovary syndrome and a research of related genes. Foreign Med Sci Obst Gynecol 34: 212-217, 2007.

9. De Ugarte CM, Bartolucci AA and Azziz R: Prevalence of insulin resistance in the polycystic ovary syndrome using the homeostasis model assessment. Fertil Steril 83: 1454-1460, 2005.

10. Steppan CM, Bailey ST, Bhat S, et al: The hormone resistin links obesity to diabetes. Nature 409: 307-312, 2001.

11. Ovalle F and Azziz R: Insulin resistance, polycystic ovary syndrome, and type 2 diabetes mellitus. Fertil Steril 77: 1095-1105, 2002.

12. Gu HF: Biomarkers of adiponectin: plasma protein variation and genomic DNA polymorphisms. Biomark Insights 4: 123-133, 2009.

13. Matsuzawa Y, Funahashi T and Nakamura T: Molecular mechanism of metabolic syndrome $\mathrm{X}$ : contribution of adipocytokines adipocyte-derived bioactive substances. Ann NY Acad Sci 892: 146-154, 1999.

14. Yokota T, Oritani K, Takahashi I, et al: Adiponectin, a new member of the family of soluble defense collagens, negatively regulates the growth of myelomonocytic progenitors and the functions of macrophages. Blood 96: 1723-1732, 2000.

15. Weyer C, Funahashi T, Tanaka S, Hotta K, Matsuzawa Y, Pratley RE and Tataranni PA: Hypoadiponectinemia in obesity and type 2 diabetes: close association with insulin resistance and hyperinsulinemia. J Clin Endocrinol Metab 86: 1930-1935, 2001.

16. Matsuzawa Y: Adiponectin and inflammation. Nutr Health 10: 111-117, 2007

17. Hara K, Boutin P, Mori Y, et al: Genetic variation in the gene encoding adiponectin is associated with an increased risk of type 2 diabetes in the Japanese population. Diabetes 51: 536-540, 2002.

18. Bouatia-Naji N, Meyre D, Lobbens S, et al: ACDC/adiponectin polymorphisms are associated with severe childhood and adult obesity. Diabetes 55: 545-550, 2006.

19. Ma J, Mollsten A, Falhammar H, et al: Genetic association analysis of the adiponectin polymorphisms in type 1 diabetes with and without diabetic nephropathy. J Diabetes Complications 21: $28-33,2007$

20. Musso G, Gambino R, De Michieli F, Durazzo M, Pagano G and Cassader M: Adiponectin gene polymorphisms modulate acute adiponectin response to dietary fat: Possible pathogenetic role in NASH. Hepatology 47: 1167-1177, 2008.

21. Vionnet N, Tregouet D, Kazeem G, et al: Analysis of 14 candidate genes for diabetic nephropathy on chromosome $3 q$ in European populations: strongest evidence for association with a variant in the promoter region of the adiponectin gene. Diabetes 55: 3166-3174, 2006.

22. Kahsar-Miller M, Boots LR, Bartolucci A and Azziz R: Role of a CYP17 polymorphism in the regulation of circulating dehydroepiandrosterone sulfate levels in women with polycystic ovary syndrome. Fertil Steril 82: 973-975, 2004.
23. Petry CJ, Ong KK, Michelmore KF, et al: Association of aromatase (CYP 19) gene variation with features of hyperandrogenism in two populations of young women. Hum Reprod 20: $1837-1843,2005$

24. Unsal T, Konac E, Yesilkaya E, et al: Genetic polymorphisms of FSHR, CYP17, CYP1A1, CAPN10, INSR, SERPINE1 genes in adolescent girls with polycystic ovary syndrome. J Assist Reprod Genet 26: 205-216, 2009.

25. Rajkhowa M, Talbot JA, Jones PW, Pettersson K, Haavisto AM, Huhtaniemi I and Clayton RN: Prevalence of an immunological LH beta-subunit variant in a UK population of healthy women and women with polycystic ovary syndrome. Clin Endocrinol (Oxf) 43: 297-303, 1995

26. Witchel SF, Kahsar-Miller M, Aston CE, White C and Azziz R: Prevalence of CYP21 mutations and IRS1 variant among women with polycystic ovary syndrome and adrenal androgen excess. Fertil Steril 83: 371-375, 2005.

27. Meigs JB, Dupuis J, Herbert AG, Liu C, Wilson PW and Cupples LA: The insulin gene variable number tandem repeat and risk of type 2 diabetes in a population-based sample of families and unrelated men and women. J Clin Endocrinol Metab 90: 1137-1143, 2005.

28. Xita N, Georgiou I, Tsatsoulis A, Kourtis A, Kukuvitis A and Panidis D: A polymorphism in the resistin gene promoter is associated with body mass index in women with polycystic ovary syndrome. Fertil Steril 82: 1466-1467, 2004.

29. Zhang N, Shi YH, Hao CF, et al: Association of $+45 \mathrm{G} 15 \mathrm{G}(\mathrm{T} / \mathrm{G})$ and $+276(\mathrm{G} / \mathrm{T})$ polymorphisms in the ADIPOQ gene with polycystic ovary syndrome among Han Chinese women. Eur J Endocrinol 158: 255-260, 2008.

30. Melistas L, Mantzoros CS, Kontogianni M, Antonopoulou S, Ordovas JM and Yiannakouris N: Association of the $+45 \mathrm{~T}>\mathrm{G}$ and $+276 \mathrm{G}>\mathrm{T}$ polymorphisms in the adiponectin gene with insulin resistance in nondiabetic Greek women. Eur J Endocrinol 161: 845-852, 2009.

31. Petrone A, Zavarella S, Caiazzo A, et al: The promoter region of the adiponectin gene is a determinant in modulating insulin sensitivity in childhood obesity. Obesity (Silver Spring) 14: 1498-1504, 2006.

32. Warodomwichit D, Shen J, Arnett DK, et al: ADIPOQ polymorphisms, monounsaturated fatty acids, and obesity risk: the GOLDN study. Obesity (Silver Spring) 17: 510-517, 2009.

33. Ma J, Mollsten A, Falhammar H, et al: gene association analysis of the adiponectin polymorphisms in type 1 diabetes with and without diabetic nephropathy. J Diabetes Compl 21: 28-33, 2007.

34. Vasseur F, Helbecque N, Lobbens S, et al: Hypoadiponectinaemia and high risk of type 2 diabetes are associated with adiponectin-encoding (ACDC) gene promoter variants in morbid obesity: evidence for a role of ACDC in diabesity. Diabetologia 48: 892-899, 2005

35. Laumen H, Saningong AD, Heid IM, et al: Functional characterization of promoter variants of the adiponectin gene complemented by epidemiological data. Diabetes 58: 984-991, 2009 . 